University of South Florida

DIGITAL COMMONS

Digital Commons @ University of

@ UNIVERSITY OF SOUTH FLORIDA

South Florida

QMaSC: A Handbook for Directors of

Quantitative and Mathematics Support Centers

USF Libraries

$1-1-2016$

\title{
23. Case Study: Math and Computer Science Academic Support Services at Bethel University
}

Patrice Conrath

Bethel University

Follow this and additional works at: https://digitalcommons.usf.edu/qmasc_handbook

\section{Recommended Citation}

Patrice Conrath (2016), "Case Study: Math and Computer Science Academic Support Services at Bethel University", http://dx.doi.org/10.5038/9780977674435.ch23 in G. Coulombe, M. O'Neill, M. Schuckers (Eds.) A Handbook for Directors of Quantitative and Mathematical Support Centers, Neck Quill Press, http://scholarcommons.usf.edu/qmasc_handbook.

This Case Studies is brought to you for free and open access by the USF Libraries at Digital Commons @ University of South Florida. It has been accepted for inclusion in QMaSC: A Handbook for Directors of Quantitative and Mathematics Support Centers by an authorized administrator of Digital Commons @ University of South Florida. For more information, please contact digitalcommons@usf.edu. 


\section{Case Study: Math and Computer Science Academic Support Services at Bethel University}

(c) Patrice Conrath, Bethel University

प्र

\section{Introduction to the Center}

Bethel University, in St. Paul, Minnesota, is a liberal arts institution serving approximately 6,000 students in both undergraduate and graduate programs [1. This case study will provide information on academic support services for undergraduate students in the College of Arts and Sciences (CAS) which has a student population of about 2,700 students. The CAS offers 88 majors and many students choose to live on-campus all four years. Bethel's College of Adult and Professional Studies and Graduate School also has an emerging center called the Academic Resource Center, which offers weekly math and writing support. This math support is available for four hours on one evening per week $(3-7 \mathrm{pm})$ and is staffed by a Master's level tutor. The rest of this document will focus on services offered to undergraduate students.

Math and computer science support services for CAS students include math placement testing, Math Lab, Computer Science (CS) Lab, and individual tutoring in addition to faculty/teaching assistant (TA) office hours. These programs exist under the umbrella of the Academic Enrichment and Support Center (AESC), which also coordinates resources including academic counseling, free peer tutoring, the Writing Center, Business Help Sessions, Science Tutor Help Sessions, Christian-

Suggested Citation: Patrice Conrath (2016), "Case Study: Math and Computer Science Academic Support Services at Bethel University ", http://dx.doi.org/10.5038/9780977674435.ch23 in G. Coulombe, M. O'Neill, M. Schuckers (Eds.) A Handbook for Directors of Quantitative and Mathematical Support Centers, Neck Quill Press, http://scholarcommons.usf.edu/qmasc_handbook

This material is based upon work supported, in part, by the National Science Foundation under Grant DUE1255945. Any opinions, findings, and conclusions or recommendations expressed in this material are those of the author(s) and do not necessarily reflect the views of the National Science Foundation 
ity and Western Civilization TA Sessions, Nursing Exam Reviews, Multilingual Student Writing Support, and Biokinetics and Applied Health Science Help Sessions.

The AESC office physical space includes offices for the co-directors, the administrative support staff, the Writing Center, and a meeting space for group tutoring sessions and staff meetings. The Math Lab and Computer Science Lab meet in three classrooms near the Math and Computer Science Department. The main classroom used by the Math Lab is a high tech student-centered active learning environment with five pods and Writewalls. The pods each seat nine students and have independent displays. Materials for the labs, including answer keys, nametags, an attendance laptop, and laptops for student checkout, are housed in a large rolling cart that is transported to the labs for each session. Tutors hang signs, including course names for grouping students, at each session and a permanent bulletin board outside the main lab gives schedule and tutor information (e.g., which student tutors are available for specific courses). Two of the classroom spaces have stayed consistent for many years, so the areas are known as the Math Lab and Computer Science Lab spaces, even though classes meet in the same rooms throughout the week.

Bethel has philosophically chosen to incorporate full-time faculty to serve as AESC directors, as a portion of their load, to build faculty buy-in and use departmental communication and collaborative best practice support in their representative fields. This model was patterned after Calvin College's academic support model when AESC first began in 1988. Shortly thereafter, Math Lab became a part of the AESC services in 1992, and the Computer Science Lab was added in 2001. The faculty-driven model gives loads for managing AESC services. While a full-time load for Bethel faculty is seven courses (three per semester and one in January), loads for managing AESC services range from one to three courses, with two faculty serving in a larger capacity as co-directors for the office. The AESC staff, which includes a full-time, ten month office manager, meets biweekly to communicate about recruitment, assessment results, logistical needs and brainstorm as a "think tank" about arising needs and challenges. The co-directors of AESC report to the Associate Dean of Academic Affairs helping to provide communication bi-directionally. This model provides naturally strong and positive relationships and communication between departments, Academic Affairs, and the AESC office which enhances staffing, training, assessment, and other efforts.

The AESC mission is to:

...develop, administer and evaluate academic support and enrichment services intended to promote students' academic success. We encourage students to identify their strengths and weaknesses as learners, observe the connection between their study strategies and their results, and to develop and implement a plan for improvement.

By including both "support" and "enrichment" in the title, the AESC office intentionally sought to welcome both struggling and advanced students to utilize its services. AESC has been successful in serving the whole student population and many students naturally include AESC services as 
part of their weekly routine. During the 2014-2015 academic year, AESC services totaled more than 11,500 student contacts, averaging about 4.39 contacts per student in CAS. Of these contacts, 4156 were realized in the Math and Computer Science labs, so these services are a significant piece of the AESC resources.

The Math and Computer Science labs align with AESC's mission and seek to provide environments that will foster growth and support opportunities for students enrolled in introductory math and computer science courses. During a Math Lab session, it's normative to find both a struggling General Education math student discovering new insights from a peer tutor's fresh explanation of a concept and Discrete Math students enjoying a lively theoretical debate over the most concise way to state a proof. Being a tutor in the Math or Computer Science lab is seen as an honor. Tutors enjoy not only the content review that naturally occurs when explaining concepts to others, but also the camaraderie and friendships that organically develop while working together in the busy labs. Bethel's Christian heritage also promotes attitudes of service and encouragement, so the environment is generally positive and non-competitive. In addition, faculty embrace these resources, regularly interacting with the tutors and lab director (their colleague) and encouraging their students to utilize the labs and tutoring services.

\section{Center Organization and Services}

All math and computer science services are coordinated by the Director of Math and Computer Science Services (Math/CS Director) who has faculty status and reports to both the Math and Computer Science Department and AESC (see Appendix A for reporting structure).

The director is responsible for math placement and skills testing, hiring, and managing tutors who serve in the Math and Computer Science Labs or work individually with students. Recently another lab director for Computer Science was added to support the growing computer science and technology aspects of the position.

Math placement exams are currently used to test students entering Precalculus and Calculus 1. Placement testing utilizes in-house developed exams and is administered using in-house developed online testing and reporting tools. Tests can be taken at any time through an online format in a "self-enrollment Moodle course." Skills testing takes place at the end of the first week of classes, holding these students accountable for learning the prerequisite material. These tests are similar to the placement exam and are considered the first exam in the course. The Math/CS Director oversees testing procedures; hires proctors; updates communication on the testing web site; interacts with the Admissions and Registrar's offices; maintains and updates forms and follow-up materials; and informs and fields questions from advisors, faculty, and students.

Student requests for individual tutors originate in the AESC office, where the student meets with an AESC counselor for an initial assessment. The counselor consults online lab attendance 
records, the student's professor, and the Math/CS Director to determine the best plan for the student. Some students are referred back to Math Lab or CS Lab, while others are assigned peer tutors who meet individually with students for approximately two hours per week. Link-ups are tracked and managed by AESC support staff, and ongoing assessment for tutees and tutors is initiated by the AESC office using a Google form. The feedback from the student (see Appendix B) is reviewed by the Math/CS Director when the individual tutor meets to discuss progress with their student(s). This meeting is also recorded using a Google form (see Appendix C).

Bethel's lab schedules differ from most large universities in that Math Lab is open for only 13 hours per week, and CS Lab is open 2 hours per week in the fall and 4 hours per week in the spring. However, within these hours, tutors have approximately 1500-2500 visits per semester and about 200 visits in January (three week interim courses). Lab hours include mostly evening hours since Bethel is a residential campus where most students are able to attend these evening sessions. Two sessions per week are provided during daytime hours for commuting students.

The CS Lab serves students in Introduction to Programming, Computer Science 1, and Scientific Computing with the following schedule in the spring semester:

Sunday: 7:45 - $9 \mathrm{pm}$

Monday: 4:15 - 5:15 pm

Tuesday: $6-8 \mathrm{pm}$

Fall semester CS Lab hours are: Sun. 8 - 9 pm, Tues. 6:30 - 7:30 pm. Math Lab serves students in Math for the 21st Century and Creative Problem Solving (General Education math courses), Math for Elementary Education 1 and 2, Statistical Analysis, Business Calculus, Precalculus, Calculus 1 and 2, Multivariable Calculus, Differential Equations, Linear Algebra, and Discrete Math, along with the Computer Science courses listed above with the schedule below:

Fall and Spring Semester Hours

Sunday: 7:30-9:45 pm

Monday: 5:45-7:00 pm

Tuesday: 4:15-5:15 pm \& 8:45-10:00 pm

Wednesday: 8:30-9:45 pm

Thursday: 10:15-11:00am \& 6:00-8:15 pm

Interim Hours (January)

Sunday: 8:00-9:30 pm

Monday-Thursday: 6-7:30 pm

Attendance at each session varies from 2 - 70 students, with highest attendance on nights before homework is due (making Sunday, Tuesday, and Thursday nights busiest). See Appendix D for a sample tutor schedule. 


\section{Staffing, Hiring, and Training}

As noted in the previous section, Math and Computer Science services are coordinated by the director who also serves as a faculty member in the Math and Computer Science Department. This director hires all math and computer science tutors, who then become employees of AESC. Some tutors engage in tutoring activities for a variety of disciplines. Tutoring is provided exclusively by undergraduate peer tutors who are often math or computer science majors and have been academically strong in the courses served by the labs. A tutor may be hired for a specific course or to work with various courses depending on their skill and interest.

To begin the process of hiring for a new semester, current tutors are surveyed using a Moodle survey to gather scheduling information and course interest (which is matched to faculty recommendation and references) (see Appendix E). Remaining positions are filled by first soliciting recommendations from Math and Computer Science faculty using a Google document. The Math/CS Director reviews tutor applications and interviews all tutor candidates (see Appendix F), contacts references, and hires the top students to serve as both individual and lab tutors.

Strong returning tutors who demonstrate the ability to multi-task are given "Lead Tutor" positions in which they not only tutor, but also manage lab sessions. These tutors have the following responsibilities: set up materials before each session, start and manage the online attendance tracking system, manage tutors to make sure students are being well served, and give feedback to the director after each session. Two student managers are also hired to help with the creation of the schedule, tutor communication, and logistical support (creating nametags, updating the tutor poster, keeping an eye on materials and signs, and other maintenance tasks). The student managers also serve as tutors, so they are intimately involved in all tutoring aspects and often bring creative ideas to improve our services.

All AESC tutors go through an initial two and a half hours of training and then continue to be trained within the discipline where they serve. General initial training topics include: understanding the AESC philosophy for creating successful independent learners, the role of tutors, tutoring multilingual learners, structuring a tutor session, learning styles, and logistical details such as timesheets and assessment. Tutors also receive continuing online training each new year, and have access to online Moodle modules on a variety of topics that may come up during tutor training (e.g., best practices for supporting students with learning disabilities, three sessions on supporting multilingual students, and using emotional intelligence in tutoring).

Math and Computer Science tutors take part in an additional two and a half introductory hours of training focused on working with math and computer science students and participate in monthly lab meetings, interspersed with periodic email communication as needs and issues arise. Lead Tutors complete an additional hour of initial training, meet biweekly with the director, and have ongoing weekly communication with the director, mainly through email and the online attendance system. 
Modes of tutor training include face-to-face meetings facilitated by the director (often jointly led with Lead Tutors), 15-minute Lead Tutor directed training sessions after lab sessions, or written communication/interactive surveys that tutors are motivated to complete online as they are paid for this flexible meeting. Lead Tutors continue to rise to the challenge of leading tutoring services and often give very insightful comments during training sessions for meeting tutoring challenges and figuring out new ways to serve our students well. Topics discussed in training include lab policies and procedures, working with large groups, helping needy students, modeling good study skills, and handling comments about professors and courses.

\section{Community Interactions}

Our unique organizational structure, where center directors also have faculty status in their representative departments, fosters healthy relationships between the Math and Computer Science services and the Math and Computer Science department. Therefore, communication issues are minimized, and there are no political issues or turf wars. The services are fully embraced, supported, appreciated, and advertised by the Math and CS professors.

To advertise our tutoring services, all students in courses served by the labs are given bookmarks with the schedule and room information on the first day of classes. Professors also include hours and information in their course syllabi and on their course pages in Moodle. We often do a second round of advertisements in each class after the first exam. Tutors share a short video presentation on our services at this point of need (when students first realize they may be struggling) and students listen to the tutor, as their peer, who encourages their attendance.

Math Lab and CS Labs have been well received and are often a part of students' normal workweek schedule. Students come to the labs to work on homework, get homework checked, or ask questions. To help those who may be more hesitant to join a group, extra "welcome tutors" are utilized during the first week of labs, to help new students sign in and find groups. Course signs hung consistently in the same locations also help students to develop patterns so they can easily find tutors and students in their classes. Our latest advertising effort is a positive, short commercial video that will be shown in classes and linked from course Moodle pages and the AESC web site to help students see the lab before they attend (somewhat like students' use of Google earth to spy on a location before they go there!). In the coming school year, we plan to improve our AESC website and testing website to provide fresh, current information (e.g., daily or weekly study tips) so that students will visit our sites on a regular basis and begin to use the preexisting study skill modules which incorporate video, handouts, and PowerPoints with Adobe Presenter (put together by the co-director of AESC for a sabbatical project [2]).

As the Math and CS services provide assistance to students in multiple departments, we gain support from other academic departments such as Business, Physics, and other sciences. No off- 
campus tutoring occurs through the Math and CS services, however many tutors do take part in tutoring in the community, and Bethel helps to coordinate some of these efforts.

\section{Assessment}

The AESC office functions as an academic department, so it takes part in Bethel's accreditation process. Bethel is accredited by the North Central Association of Colleges and Schools of Higher Learning. Therefore the AESC office submits a report of activities, assessment results, and documentation of the use of data to improve services, which are spearheaded by AESC's student learning objectives. The AESC faculty team created an assessment outcomes map which specifies when and which assessments are used to assess student learning outcomes. This team recently engaged in creating new assessments in the area of tutor enrichment. This report is reviewed Bethel's administration annually and the accreditation team.

Internal assessments happen in several different formats. As stated above, tutors working individually with students must meet with the Math/CS Director periodically to discuss their tutoring link-up. Those receiving services are also required to submit feedback using a Google form (see Appendix B). The director is able to access these student comments during the meeting, and most students agree to share their comments with the tutor. These comments are fruitful for providing encouragement for the tutor and discussing issues and perceptions of the student. Strategies for improving the tutee's academic achievement (e.g. study skill changes perhaps directing students to the online study skills workshops [2]) and to build the relationship are discussed and meeting notes are recorded on a Google form (see Appendix C). The AESC office manager tracks these Google forms to ensure that appointments between the tutor and director happen. Pay is withheld until the assessment is complete.

Communication between tutors and the director happens at the end of each tutor lab session via an automated e-mail through the online attendance system. As each system closes, an email with attendance figures and tutor comments is sent to the director and any interested professors. This allows for immediate attention to any issues that arise in the session. Lead Tutors also give great feedback from each session and help to tackle any problems or issues that may arise in the sessions. Often, a week before a monthly training meeting, Lead Tutors are contacted to add comments to a Google docs brainstorming document. Lead Tutors share current issues and training needs, and strategies are discussed. Then, each Lead Tutor is assigned a topic to discuss at the next meeting. Lively discussions occur at these meetings as tutors usually have bright ideas for dealing with issues and have an intimate understanding of the student culture and courses, since many of them had the same professors. Also, we find that tutors who may have heard the same exact training topics at the initial training are usually more attentive to the same training content when delivered by a peer tutor using language and scenarios they now understand. Tutors also email professors with 
comments specific to their courses after each session. This active communication network improves our services and also lets students know that their specific needs are supported and handled with care.

More formal assessment of the labs and tutors happens at the end of each semester. All lab attendees are sent a link to an online assessment using a Qualtrics survey (see Appendix G). Tutors also complete an AESC Tutor Self-Assessment \& Enrichment Survey through Qualtrics (see Appendix H). These tools provide valuable comments for encouraging tutors and improving our services and training. The director reviews these comments, implements changes, and often uses direct quotes from the surveys in training materials to add power to a training point.

\section{Additional Topics}

In this section, two special features of Bethel's Math and Computer Science services will be highlighted along with a current issue we are facing.

In-house Developed Attendance Systems: In 2003, we recognized the need for moving beyond paper sign-ins to an automated system. So, during the fall 2003 semester, students in the Computer Science course, Web Programming, focused their efforts on creating an attendance system. The professor used a competition to motivate student teams to produce a quality product. The winning team members were hired to complete the attendance and reporting application during the spring semester, and it was implemented in the Math Lab during the next academic year. Since then, students were employed to create similar attendance and reporting systems for other labs, providing useful reports and communication for AESC staff, instructors, tutors, and the directors.

The systems needed to be updated, so after reviewing commercial software and finding them deficient, we decided to once again create an in-house developed attendance tool with oversight from our Information and Technology Services department. The tool is now a unified AESC attendance application that provides attendance records, reports, and easy mechanisms for communication. Although the start-up investment is high in this type of application, we have found that it is very beneficial to have customized reports and other functions that fit our needs and unique schedules. Utilizing students to help create the application also makes this option cheaper and provides a wonderful real life application for their Web Programming course.

Strong Community Atmosphere: When discussing tutor recruitment with colleagues from other universities, some have noted that recruiting tutors is extremely difficult. At Bethel, we are usually able to develop a strong team of tutors. Tutoring is viewed in a positive light, and often as an act of service. Those who tutor upper division courses wear this like a badge of honor and majors strive to have all courses listed on the schedule by their name. The professors also encourage students to serve in the labs. If students do well in a class, they are often expected to tutor for that course. Students are assigned a session for the semester along with two to ten other tutors, so 
they enjoy working together and become close to this group of colleagues as they serve the students together. Several students have developed a love for teaching through their service in the labs. Community is also developed through activities such as student designed t-shirts and Math and CS Lab pizza parties where students create their own math and CS shaped pizzas.

Current Issues - Supporting Students with Skill Deficits: At Bethel, we have recently noticed a downward trend in the entry-level mathematics proficiency of students enrolling in General Education and foundational business classes that require math content. While our professors have raised questions about the quality of some of these incoming students, the admissions personnel and Vice President of Data Enrollment and Management contend that the ACT average has remained relatively stable over several years. They do, however, state that the variance among ACT sub-scores has changed. This seems to be the result of students excelling (perhaps choosing to specialize) in one content area to the detriment of another. Consequently, a student may have outstanding English or reading scores but post extremely low math scores, resulting in a reasonably acceptable ACT composite score. This could then support the observations of both math faculty and admissions personnel that increasing numbers of Bethel students have sub-par ACT math scores accompanied by relatively stable ACT composite scores. There are some interesting observations relating ACT scores to college success found in an "Inside Higher Ed" article, "ACT's Validity Questioned" [3] that relate to this difference between composite and sub-scores.

Bethel offers General Education math courses, but a course sequence for math and science majors begins with Precalculus. Thus, we do not offer any developmental math courses. In order to ensure that students can complete the courses successfully, we currently test for placement into Precalculus and Calculus 1. For these students, Bethel offers two ALEKS preparatory courses allowing them to complete a more in-depth review of Bethel's prerequisite course objectives. We have chosen ALEKS, because it develops a plan for remediation that is tailored to specific student needs (as opposed to more rigidly structured packaged courses). ALEKS also has learning modules that are not "template math" and seem to follow good pedagogical methodology, focusing on conceptual understanding versus procedural fluency. Students in Calculus 1 self-remediate quickly, if needed, in preparation for a "Skills Test" given early in the Calculus 1 course. This test holds them accountable for their preparation. Precalculus students are also given a plan for self-remediation prior to the "Skills Test"; some take the time to do the remediation and some drop out.

Prospective elementary teachers who wish to enroll in the first of two math content courses must also satisfy certain prerequisite skills criteria. Those with ACT or SAT scores must:

- have scored 24 or higher on the math portion of the ACT, or

- have scored 560 or higher on the math portion of the SAT score, or

- successfully complete Bethel's ALEKS Math for Elementary Education Prep course Those without ACT or SAT scores must: 
- successfully complete Bethel's ALEKS Math for Elementary Education Prep course (recommended), or

- score at or above the $80 \%$ level on the Math for El.Ed. Pretest

Given our initial success with ALEKS remediation in prerequisite skills for Math for El. Ed. 1, we have become interested in expanding our use of ALEKS to other courses. It is our hope to find ways to better facilitate success in our entry level math courses by channeling underprepared students through appropriate ALEKS courses prior to enrollment. This plan will give students, from a variety of courses, an additional options for shoring up their skills before taking a course.

\section{Acknowledgments}

I would like to thank Dr. Ruth Nelson, AESC Co-director and Associate Professor of Psychology and Jesse Cabak, middle school math teacher, and former Math Lab tutor for their editing help. Thank you also to Dr. Scott Brown, Professor of Mathematics, contributing editor for part 5, "Current Issues".

We would like to thank the National Science Foundation for its generous support of the QMaSC Workshop through NSF grant number 1255945. Any opinions, findings, and conclusions or recommendations expressed in this material are those of the author(s) and do not necessarily reflect the views of the National Science Foundation.

\section{Bibliography}

[1] "Bethel at a Glance." http://www.bethel.edu/about/bethel-glance/, Accessed: March 2, 2016.

[2] S. Mulberry, "On-line Study Skills Workshops." https://googledrive.com/host/ OB-iVbRlqYrPLVmdLOWtMbkFSdOk/AESC-Study-Skills-Workshops.htm, 2010. Accessed: March 2, 2016.

[3] S. Jaschik, "ACTs Validity Questioned." Inside Higher Ed., June 21, 2011. http: //www.insidehighered.com/news/2011/06/21/study_suggests_most_colleges_use_ act_inappropriately. 


\section{Appendix A: Institutional Structure for Bethel Math and Computer Science Services Director}

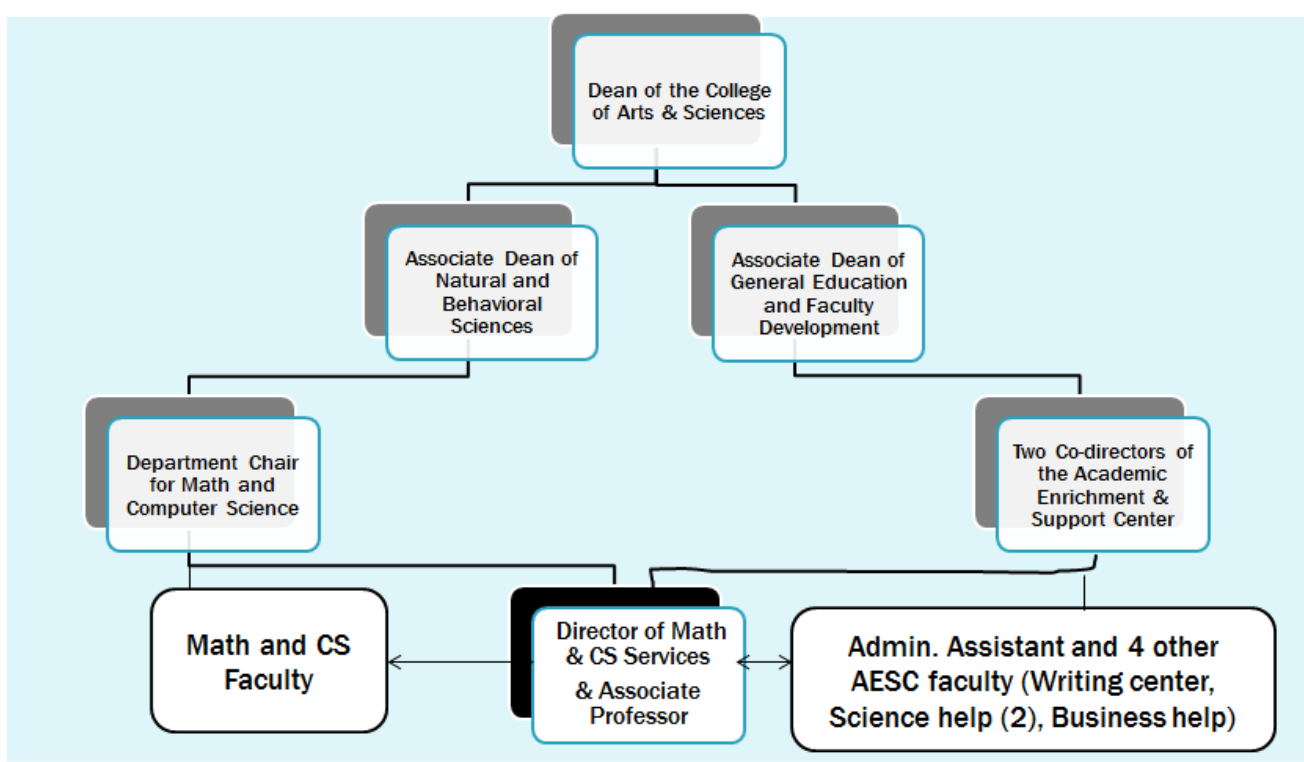

Figure 1: Sample Reporting Structure for the Director of Math and Computer Science Services

\section{Communication and Meetings:}

1. Math and Computer Science Department Chair \& Faculty: regular, daily communication takes place through hallway conversations, meetings and email

2. AESC Faculty: bi-weekly meetings in the AESC office and email communication as needed

3. Associate Dean of General Education and Faculty Development: monthly reports are submitted by the Math and Computer Science Services Director to the Co-directors of the AESC office who bring the AESC office report to their monthly meeting with the Associate Dean. 


\title{
10 Appendix B: Student Tutor Relationship Google Form Assessment
}

\author{
How are Things Going With Your AESC Tutor?
}

Please answer the questions below in regards to the individual AESC tutoring you've been receiving this semester.

${ }^{*}$ Required

Your Full Name (First and Last): * $\sqrt{\text { StudentName }}$ Name of tutor: * $\sqrt{\text { TutorName }}$

Course in which you are tutored: * ${ }^{\text {Calc. } 1}$

Number of hours you spent with your tutor last week? *

2 hours $\quad+$

Number of hours you spent with your tutor this week? *

2 hours $\quad-$

Do you have a regular schedule for tutoring? * Yes

Did you contact your prof. for help this week? * Yes

Did you attend all classes and labs this week? * ${ }^{\text {Yes }}$

In the last week, how much time did you spend reading your textbook(s) for this

class?*

In the last week, how much time did you spend reviewing class notes for this

class? * 3 hours =

In the last week, how much time did you spend completing homework/assignments for this

class?* $31 / 2$ hours

Are you attending the help session or tutoring lab that applies to your course?

In the last week, how many TOTAL hours did you spend studying? *

Yes

Yes

How do you rate your current understanding of the course material? *

$\begin{array}{lllll}1 & 2 & 3 & 4 & 5\end{array}$

Very confused $\odot \quad \odot \quad \odot \quad \odot \quad \odot$ Understand well

How do you rate your ability to keep up in this course? *

$\begin{array}{lllll}1 & 2 & 3 & 4 & 5\end{array}$

Impossible to keep up $\odot \quad \odot \quad \bullet \quad \odot \quad \odot$ Very confident I can keep up

What are you doing to improve your tutoring sessions and experiences in the course? ${ }^{*}$ \{text box\} What teaching techniques did your tutor use that really helped? * $\{$ text box

Have you tried more effective ways to study for your course based on your tutor's suggestions? \{yes,

no\}. If "yes", how are you studying differently? \{text box\}

What additional support would be helpful for your success in this class? \{text box\}

Is it OK if we share your responses with your tutor? * ${ }^{\text {Yes }}$ 


\section{Appendix C: Tutor Interaction Assessment Google Form}

\section{AESC Tutor Link-up Evaluation Form}

This form is used to evaluate the tutor's link-up with their tutee. It is filled out during the tutor's meeting with one of the AESC lab directors or counselors.

* Required

Tutor Name (Your Name): * $\sqrt{\text { TutorName }}$ Tutee Name: *

Course in which the student is being tutored: * $\sqrt{\text { Precalc. }}$ Professor $\sqrt{\text { ProfName }}$

Are you regularly meeting with your tutee? *

- Yes $\mathrm{No}$

In the last two weeks, how many hours have you spent meeting with the

student? *

2 hrs $\quad-$

How well prepared is the student when they come to meet with you? *

$\begin{array}{lll}1 & 2 & 3\end{array}$

Not Well Prepared $\odot \quad \odot \quad \bullet \quad$ Well Prepared

Please comment on your sessions with this student. How do you generally feel the sessions are going? What does a typical session look like (i.e. what do you do in meetings with the student)? * \{text box

Do you feel the student has improved in their understanding of course material? *

- Yes $C$ No

Do you feel the student has improved their study skills or study methods in the time you have worked with them? *

- Yes $\mathrm{No}$

Do you have any problems or concerns relating to this tutor link-up? *

C Yes No

If you answered "YES" to the question above, please explain your problems or concerns.

$\sqrt{v}$ Send me a copy of my responses. 


\section{Appendix D: Sample Math and CS Lab Schedules}

\section{羂Math Lab \\ Bethel Math Lab, Spring 2016 Schedule}

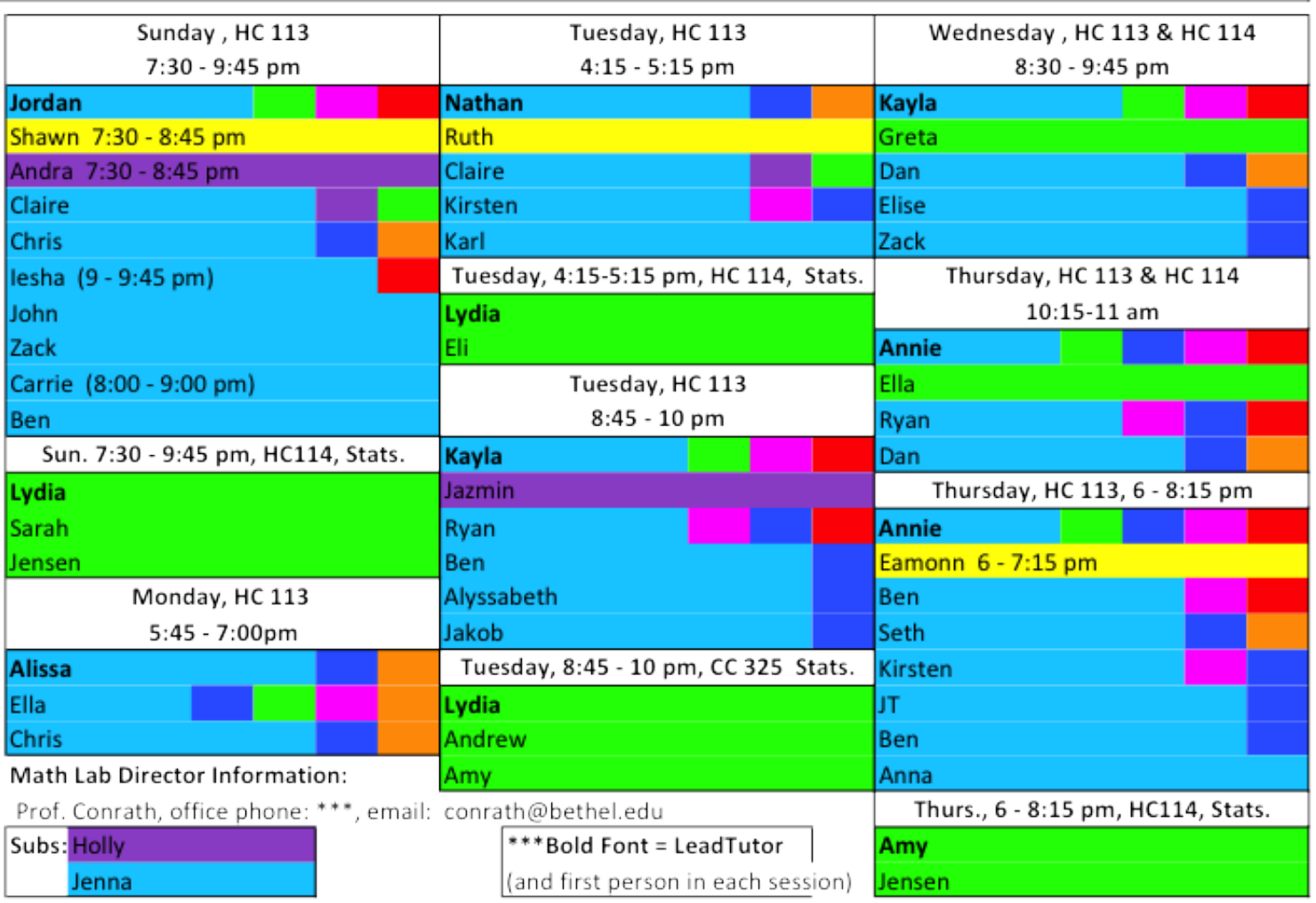

\begin{tabular}{|l|l|l|l|l|l|l|l|}
\hline Courses & Precalc./ & Multi. & Math for & Math for & Statistical & Linear & Differentia \\
\hline
\end{tabular}

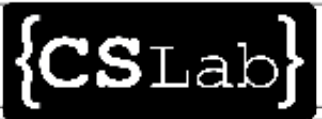

Bethel CS Lab, Spring 2016 Schedule Sunday 8-9 pm
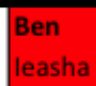

\begin{tabular}{|l|l|l|}
\hline $\begin{array}{l}\text { Monday } \\
\text { 5:15-6:15 pr }\end{array}$ & Peter & $\begin{array}{l}\text { Tuesday } \\
6-8 \mathrm{pm}\end{array}$ \\
\hline
\end{tabular}

Serving Students from Computer Science 1 in CC230

CS Lab Director Information: Dr. Thomas, office phone: ****, email: ****

\begin{tabular}{|l|l|l|}
\hline $\begin{array}{l}\text { Annie } \\
\text { Nadia } \\
\text { on call: Ben }\end{array}$ & $\begin{array}{l}\text { Sub } \\
\text { List: }\end{array}$ & $\begin{array}{l}\text { Kayla } \\
\text { Jordan } \\
\text { Ben }\end{array}$ \\
\hline
\end{tabular}




\title{
13 Appendix E: Moodle Returning Tutor Survey
}

\author{
Current Math Lab \& CS Lab Tutor Survey For Fall 2013
}

Thank you for filling out the Math Lab \& CS Lab survey. We will be recruiting new tutors soon, so we want to know if you are returning. Please fill this survey out by Tues. April 9, 2013, 10:15 am.

Question \#1, Response Required

Please check all that apply:

$\sqrt{\checkmark}$ I would like to work in Math Lab this Fall(courses \& times are similar to the spring schedule)

$\sqrt{\checkmark}$ I would like to be an individual math tutor for Fall 2013 semester (this means that I am willing to work individually with at least one student, about 2 hours/week)

$\Gamma$ I would like to work in CS Lab this Fall(the course will be Scientific Computing, times will be similar to spring)

$\Gamma$ I would like to be an individual C.S. tutor for Fall 2013 semester (this means that I am willing to work individually with at least one student, about 2 hours/week)

$\Gamma$ I will not be able to work in Math Lab or CS Lab this next fall (go on to question \#2).

Appendix E: (continued)

Question \#2, Response Required

If you are NOT returning as a tutor, please state why (for example, "graduating").

Then, you are done with the survey and can submit it after this question. Thank you!

Question \#3, Response Required

If you will be returning, please mark all courses you feel confident tutoring:

$\Gamma$ Math for the 21st C $\square$ Math for El. Ed. $1 \quad \Gamma$ Math for El. Ed. 2

$\sqrt{\downarrow}$ Precalc., Calc. I \& Bus. Calc. $\sqrt{\downarrow}$ Calc. II $\Gamma$ Multi. Calc.

$\Gamma$ Stat. Anal. $\Gamma$ Discrete (only fall) $\quad$ Diff. EQ (only spring)

$\sqrt{\searrow}$ Linear (only spring) $\Gamma$ Intro. to Computing (fall \& interim)

『 Scientific Computing (only fall) $\quad \square$ C.S. 1 (only spring)

The following two questions relate to Fall '13 Math Lab, skip if you won't be working in the Fall

Question \#4, Response Required

I would like to work this many times per week in the lab this fall in Math Lab:

$\Gamma_{1} \Gamma_{2} \Gamma_{3} \Gamma_{4}$

Question \#5, Response Required

I am available to work the following times for fall Math Lab (we will only schedule you a maximum of the number of times you listed above, please list all times you are available):

$\Gamma$ Sundays: 7:30-9:45 pm $\sqrt{\curlyvee}$ Mondays: 5:45-7 pm $\Gamma$ Tuesdays: 4:15-5:15 pm

$\sqrt{\checkmark}$ Tuesdays: 8:45-10:00 pm ${ }^{\sqrt{ }}$ Wednesday: 8:30-9:45 pm ${ }^{\Gamma}$ Thursdays: 10:15-11am

$\sqrt{\checkmark}$ Thursdays: 6:00-8:15 pm (Similar questions follow related to CS Lab) 


\section{Appendix F: Initial Tutor Interview Form}

Bethel Math/CS Tutor Initial Interview - Day/Date/Time:

$5 / 8 / 12$

Potential Tutor

1. Which courses are you interested in tutoring? Where did you take these courses and who was/were your profs.? Classes to tutor: Math for the 21st Creative Prob. Solving Math for El. Ed. 1 or/and 2 PreCalc.

Bus. Calc. Calc. I Calc. II Multi. Stats. Discrete C.S. 1 Intro. to Programming Linear Diff EQ

2. Why are you interested in tutoring?

3. What are some of your past experiences that may be useful for a tutoring experience?

4. Why do you think the area you will be tutoring in is difficult for some students? How would you deal with someone who is very anxious?

5. Your job as a tutor involves helping the person you are working with to also become a better student. What kinds of study habits, specific to math, do you have that would be helpful to communicate with other students? (... discuss test preparation strategies too)

6. What do (did) you like about the course(s) you would like to tutor?

7. Describe the tutor training, hook-up, and check-up process. References. Questions?

\begin{tabular}{lc}
\hline Indiv? Y N & Ap sent to Vicki? \\
M.L.? Y N Hrs that DONT work: & Updated google doc__ \\
Emailed References?__ Heard back?_ ok? __ & Rxn: \\
Tutor notified? &
\end{tabular}




\section{Appendix G: Qualtrics Bethel Lab Attendee Survey}

1. How often do you visit the Math Lab? \{responses: I've only been to Math Lab once, Once/month, Every other week, Once/week, 2-3 times/week, 4-5 times/week

2. Which math course(s) have you received math support for: $\{$ responses: all courses served are listed\}

3. If you have gone to Math Lab once or twice, please explain why you dont attend the lab more regularly. \{response: text box

4. If you regularly attend the Math Lab, what do you find to be the most helpful for you? \{response: text box

5. If you regularly attend Math Lab, what could we do to improve our services? \{response: text box $\}$

6. If your instructor gave extra credit for attending Math Lab, how much did the extra credit incentive influence your attendance? \{responses: Not at all. I would have come if extra credit was not offered, Somewhat, A lot, The only reason I attended was for the extra credit, The only reason I attended at first was the extra credit but then I kept coming because it was helpful.\}

7. Any other comments or specific feedback? Suggestions? Thank you for taking the time to complete this survey. \{response: text box 


\section{Appendix H: Tutor Self-Assessment Survey}

Bethel AESC Tutor Self-Assessment \& Enrichment Survey

A. How many semesters have you tutored? Answers: 18

B. What area(s) do you tutor in? Answers: Math, Computer Science, Sciences (Biology \& Chemistry), Business \& Economics, Writing Center, Nursing, CWC, Physics, Other

C. What type of tutoring do you engage in? Answers: Help Session/Lab, Individual tutoring

D. Please answer each of these questions as it relates to your tutoring experiences. Thank you for your honest feedback! Answers for the following questions are: Strongly Agree, Agree, Neither Agree nor Disagree, Disagree, Strongly Disagree, N/A

1. Tutoring increased knowledge in content \& study strategies.

2. Tutoring helped me to review and better understand course material.

3. Tutoring helped me make connections from prior courses to current courses.

4. Tutoring has increased my confidence in the subject matter.

5. Tutoring has increased my understanding of effective study strategies.

6. Tutoring has increased my own time management skills.

7. Tutoring increased teaching skills.

8. Tutoring has increased my ability to facilitate discussion or group problem solving.

9. Tutoring has helped me to learn multiple ways of explaining and approaching problems.

10. Tutoring has increased my listening skills.

11. Tutoring has increased my ability to problem-solve, especially in the moment.

12. Tutoring has helped me to ask better leading questions.

13. Tutoring has helped improve my communication skills.

14. Tutoring helped with future vocational preparation.

15. Tutoring has helped me develop and further refine skills for my future profession.

16. Tutoring has helped with my acceptance to graduate school.

17. Tutoring has made me more employable (e.g., internships, summer jobs, post school jobs).

18. Tutoring has further developed leadership skills (e.g., managing an individual link-up or organizing small or large group sessions).

19. Tutoring helped with interpersonal skills \& character development. 
20. Tutoring has increased my interpersonal skills such as reading students' nonverbals and deescalating students' anxiety and frustration.

21. Tutoring has helped me to develop deeper empathy for students.

22. Tutoring has increased my patience.

23. Tutoring has brought humility to my learning.

24. Tutoring has helped me to work more effectively with other students.

25. Tutoring has positively impacted my overall ability to relate to other students.

26. Tutoring has provided intrinsic benefits.

27. Tutoring allows me to use the gifts God has given me to serve others.

a) Tutoring has shown me that I enjoy helping students learn.

28. Tutor training (AESC tutor training and training sessions with tutor coordinators) prepared me well for tutoring students.

E. What additional training would have been beneficial?

F. Give any ideas you have for improving the effectiveness of our services.

G. If you are discontinuing your work with AESC, explain why. If you are continuing to tutor next semester, explain why.

H. Are there any additional benefits of tutoring you have experienced? 